\title{
Rapid One-Step Fabrication of Graphene Oxide-Decorated Polycaprolactone Three-Dimensional Templates for Water Treatment
}

Andrea Maio, Michele Gammino, Emmanuel Fortunato Gulino, Bartolomeo Megna, Pierluca Fara, and Roberto Scaffaro*

Cite This: ACS Appl. Polym. Mater. 2020, 2, 4993-5005

Read Online

ACCESS | Lلlll Metrics \& More | 回 Article Recommendations | (1) Supporting Information

ABSTRACT: Coating of flexible substrates is crucial to prepare versatile, multifunctional materials. However, exploration of effective fabrication approaches is still a challenging issue, because the pathways generally proposed require time-consuming, multistep protocols. Here, we developed a one-pot process for decorating either pearl necklace-like or fibrous fluffy-like structures of polycaprolactone (PCL) with graphene oxide (GO) skin. PCL solutions were dry jet-wet electrosprayed or electrospun into a stirred liquid collector constituted by ethanol-containing GO nanoparticles. The stirred liquid collector enables the formation of $3 \mathrm{D}$-structures, whose microarchitecture can be designed by controlling the
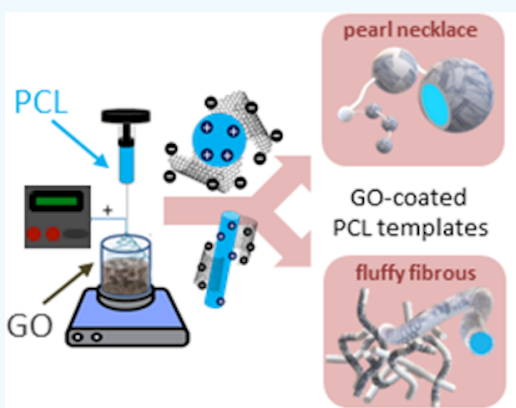

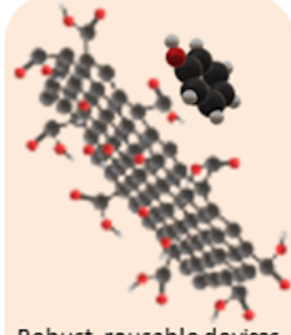

Robust, reusable devioes for phenol removal rheological behavior of PCL solutions. Two molecular weights of PCL were used ( 45 or $80 \mathrm{kDa}$ ) with ensuing different viscosity, which determines the prevalent formation of beads or fibers. The presence of GO in the coagulation bath allows the polymeric structures to be rapidly wrapped by those nanoparticles. Graphenic coating endows these materials with the intriguing peculiarities of GO: PCL/GO nanocomposites displayed increments of elastic modulus ranging from $1250 \%$ (beads) to $3300 \%$ (fibers) with respect to the neat matrices and a change from hydrophobic to amphiphilic character. A potential application of such devices in water treatment was assessed in phenol removal. The results pointed out that PCL/GO scaffolds retain the same sorption capacity of GO nanoparticles, while bringing several advantages in terms of handling, robustness, and recyclability. The ease of control of the process, as well as its fastness and cost-effectiveness could open a wide range of scenarios, including sensors, energy, catalysis, biomedicine.

KEYWORDS: 3D electrospinning, dry jet-wet-electrospinning, beads, fibers, hierarchical structure, graphene coating, phenol removal

\section{INTRODUCTION}

The possibility to obtain well-orchestrated polymeric architectures represents an emerging field of materials science for the development of advanced materials, including drug delivery devices, mimics of biological tissues, nanoreactors, and multifunctional coatings. ${ }^{1-3}$ Dry jet-wet electrospinning (or electrospraying) is one of the most promising techniques to fabricate 3D scaffolds, along with centrifugal spinning and pressurized gyration. ${ }^{4}$ In fact, beyond the rapidity of the process, this approach provides accuracy in size control and tunable surface morphologies, including surface roughness and wettability, by adjusting process parameters. ${ }^{5}$ Meanwhile, graphene oxide (GO) stimulated the interest of several researchers as a promising filler for polymer nanocomposites. ${ }^{6}$ In fact, GO is known to possess, depending on its oxidation level, tunable physical-chemical characteristics, including optical, electrical, mechanical, antimicrobial properties, biocompatibility, UV-blocking, catalytic activity, and affinity to a wide range of pollutants. ${ }^{7-12}$ Moreover, it can be easily reduced into graphene or chemically modified, thus holding promising potential as a versatile building block for the realization of nanostructured devices. ${ }^{13-15}$ Although many studies reported on the preparation of nanocomposites achieved via incorporation of GO inside the polymer matrix, ${ }^{16-18}$ only recently did surface functionalization of flexible substrates with GO attain a rising interest. ${ }^{6}$

In fact, the prospect of gathering the unique properties of this nanomaterial with the ease of processability and freestanding properties of polymers into a lightweight device via GO-coating of polymers finds application in an extremely wide range of fields, including nerve tissue engineering, electronics,

Received: August 6, 2020

Accepted: September 9, 2020

Published: September 9, 2020 
water treatment, sensors, and energy storage. ${ }^{19-22}$ Up to date, GO-coatings were accomplished by chemical methods, such as covalent binding, or by means of multistep protocols, involving the fabrication of polymeric substrate and the subsequent vacuum filtration-aided coating, dip-coating or spray-coating. ${ }^{23}$

Among the polymers, polycaprolactone (PCL), a biocompatible aliphatic polyester, encountered an increasing demand in biomedicine and membrane science over the last decades, since it can be used under harsh mechanical, physical, and chemical conditions without significant loss of properties. ${ }^{24-27}$ Furthermore, its superior rheological and viscoelastic properties over most of the aliphatic polyesters render PCL extremely easy to process and manipulate into a broad range of items. ${ }^{26}$ This latter feature enables PCL as a promising template material, serving as a substrate for GO. To the best of our knowledge, no study reported the possibility to prepare GOcoated hierarchical polymeric structures in a fast, one-step method, such as electrospinning or electrospraying a polymer solution into an active liquid collector. This novel approach promises to speed up the way to prepare hierarchical structures coated with GO, such that exploiting the numerous advantages of the latter, in terms of mechanical stiffness, amphiphilicity, electrical conductivity and capacitance, cell adhesion and cytocompatibility, catalytic activity, UV-shielding efficiency, and pollutant sequestration, thus pave the road for fast and cost-effective fabrication of multifunctional materials. In detail, here we present for the first time the possibility to obtain pearl necklace-like or fibrous hierarchical structures constituted by GO-coated PCL by either electrospraying or electrospinning PCL solutions into a liquid collector in which GO lamellae $(0.5 \mathrm{mg} / \mathrm{L})$ are suspended in an ethanol bath.

The method herein proposed allows full control of materials designed at different levels. In fact, at macroscale the choice of an appropriate solvent determines the arrangement of the polymeric architectures into $3 \mathrm{D}$ monoliths. At a microscale level, the polymer rheological parameters determine the prevalence of pearl necklace-like or fibrous structures, respectively. Ultimately, at the nanoscale level the presence of GO lamellae dispersed into a liquid collector allows the uniform coverage of polymeric structures with GO, thus enabling one to gather the advantages of polymer and graphene oxide into a unique, highly organized, core-shell structure.

Of course, the presence of GO on the surface opens an extremely wide variety of scenarios. Among the possible multiple applications of such hybrid materials, in the frame of this work we propose a preliminary study on the suitability of such systems to be adopted as reusable materials for phenol removal from water. In fact, beyond the typical requirements in terms of mechanical robustness, low density, high levels of specific area, and suitable wettability, novel materials for water treatment are required to purify contaminated waters using the lowest possible temperature/energy in order to minimize environmental and economic impact. ${ }^{28,29}$ In this perspective, materials that provide even full reusability are preferable. ${ }^{28,29}$ In the case of phenolic compounds, adsorption and photocatalysis are the two most promising technologies with the former one being particularly attractive when coupled with the possibility to easily recover the contaminants in compliance with zero-waste and circular economy concepts. ${ }^{29-31}$ In this sense, combining the properties of a biodegradable, flexible, recyclable PCL with the well-known GO affinity to phenol molecules might stimulate the fabrication of next generation systems for wastewater treatment.

\section{EXPERIMENTAL SECTION}

Materials and Reactants. PCL45 $\left(M_{\mathrm{w}}=45 \mathrm{kDa}\right)$ and PCL80 $\left(M_{\mathrm{w}}=80 \mathrm{kDa}\right)$, dichloromethane (DCM), ethanol (EtOH), deionized distilled water (DDW), diiodomethane, diethyl ether, $\mathrm{KMnO}_{4}, \mathrm{H}_{2} \mathrm{SO}_{4}, \mathrm{H}_{3} \mathrm{PO}_{4}$, and phenol were purchased by SigmaAldrich. All of the reactants were ACS grade and used without any further treatment.

Synthesis of Graphene Oxide. GO was synthesized starting from natural graphite by using Tour's method ${ }^{32}$ according to our previous works., $14,33-36$ Briefly, graphite powder $(10 \mathrm{~g})$ and $\mathrm{KMnO}_{4}$ $(60 \mathrm{~g})$ were added to $\mathrm{H}_{2} \mathrm{SO}_{4} / \mathrm{H}_{3} \mathrm{PO}_{4}$ (9:1 by volume) mixture (900 $\mathrm{mL}$ ) and kept for $16 \mathrm{~h}$ under continuous stirring. Thereafter, the reaction was quenched with $\mathrm{H}_{2} \mathrm{O}_{2}\left(30 \mathrm{wt} \%\right.$ in $\left.\mathrm{H}_{2} \mathrm{O}\right)$, and ice. For the work up, several centrifugations were carried out with $\mathrm{HCl}, \mathrm{H}_{2} \mathrm{O}$, and ethanol (EtOH). More details can be found elsewhere $e^{9,14,33-36}$ and in SI (Figures S1-S4).

Preparation Route of PCL-Based Scaffolds. For the preparation of the scaffolds, we designed a vertical electrospinning setup equipped with a stirred coagulation bath, acting as a liquid collector (Figure 1).

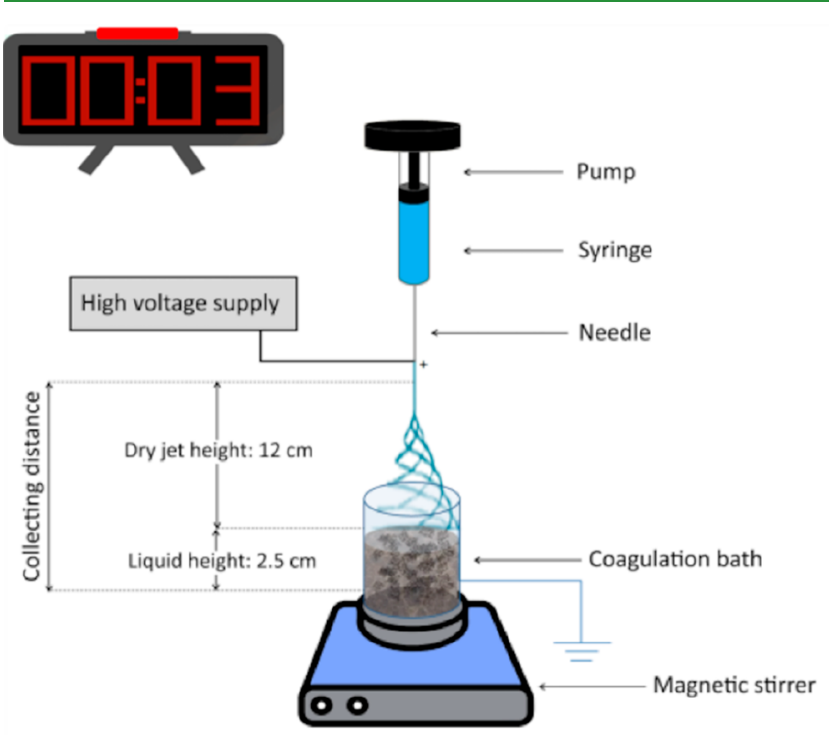

Figure 1. Experimental setup used for dry jet wet electrospinning.

All of the solutions were prepared by dissolving PCL (10 wt \%) in $\mathrm{DCM} / \mathrm{EtOH}$ (3:1 by volume) solvent mixture under gentle stirring and loaded $(10 \mathrm{~mL})$ to a glass syringe equipped with a $19 \mathrm{G}$ stainless steel needle (diameter $=0.8 \mathrm{~mm}$ ).

Furthermore, the following operating parameters were kept constant: voltage $(17 \mathrm{kV})$, flow rate $(1.19 \mathrm{~mL} / \mathrm{h})$, dry jet height $(12 \mathrm{~cm})$, liquid height $(2.5 \mathrm{~cm})$, and processing time $(3 \mathrm{~min})$. As illustrated in Table 1 , four different samples were therefore fabricated by changing PCL molecular weight and composition of coagulation bath, whose characteristics in terms of surface tension and electrical conductivity are reported in the same table. The choice of ethanol as a coagulation bath was motivated by its lower density with respect to PCL and by a sufficiently low surface tension, almost unaltered by the presence of GO. In fact, previous studies ${ }^{37,38}$ demonstrated that using liquids with high surface tension, such as pure water $(70 \mathrm{mN} / \mathrm{m})$, hinders the fibers to dip, thus resulting in a floating liquid collector to prepare $2 \mathrm{D}$ structures. Whether the fibers are able to sink into the stirred liquid collector, they will be organized into a 3D structure due to the so-called flow-induced memory ${ }^{38,39}$ and thereby frozen by the solvent migration from the polymer to coagulation bath, which leads to unique morphology and emerging properties. ${ }^{38}$ Moreover, ethanol 
Table 1. Samples Prepared at Varying $M_{w}$ of PCL and Composition of Coagulation Bath

\begin{tabular}{|c|c|c|c|c|}
\hline \multirow[b]{2}{*}{ sample } & \multirow[b]{2}{*}{$\begin{array}{c}M_{\mathrm{w}} \\
(\mathrm{kDa})\end{array}$} & \multicolumn{3}{|c|}{ coagulation bath } \\
\hline & & composition & $\begin{array}{l}\text { surface } \\
\text { tension } \\
(\mathrm{mN} / \mathrm{m})\end{array}$ & $\begin{array}{c}\text { electrical } \\
\text { conductivity } \\
(\mu \mathrm{S} / \mathrm{cm})\end{array}$ \\
\hline PCL45 & 45 & $\mathrm{EtOH}$ & 27.3 & 0.7 \\
\hline PCL80 & 80 & $\mathrm{EtOH}$ & 27.3 & 0.7 \\
\hline PCL45/GO & 45 & $\begin{array}{l}\mathrm{GO} \\
(0.5 \mathrm{mg} / \mathrm{L}) \\
\text { in } \mathrm{EtOH}\end{array}$ & 28.1 & 19.9 \\
\hline PCL80/GO & 80 & $\begin{array}{l}\mathrm{GO} \\
(0.5 \mathrm{mg} / \mathrm{L}) \\
\text { in } \mathrm{EtOH}\end{array}$ & 28.1 & 19.9 \\
\hline
\end{tabular}

is nontoxic, volatile, and particularly suitable for achieving stable GO suspensions, which are used in this study with the purpose of attaining for the first time the GO-coating of PCL-based structures in a simple, rapid, and inexpensive way.

Characterization Techniques. Rheological behavior of the solutions was investigated by using a rotational rheometer (Mars, Thermo Fisher Scientific, Waltham, MA, U.S.A.) in oscillatory frequency sweep mode using a $25 \mathrm{~mm}$ parallel-plate geometry. Measurements were performed at $25{ }^{\circ} \mathrm{C}$ at a constant stress of $1 \mathrm{~Pa}$ within the angular frequency range $0.5-100 \mathrm{rad} / \mathrm{s}$.

Attenuated total reflection Fourier transform infrared (FT-IR/ ATR) measurements were carried out by means of a FT-IR/NIR Spectrum 400 spectrophotometer (PerkinElmer, Waltham, MA, U.S.A.) in the range $4000-450 \mathrm{~cm}^{-1}$.

Micro-Raman spectroscopy was carried out in the wavenumber region of $700-3299 \mathrm{~cm}^{-1}$ by means of a Renishaw InVia instrument (Renishaw, Wotton-under-Edge, U.K.) with diode laser excitation at $633 \mathrm{~nm}$ and spectral resolution equal to $1 \mathrm{~cm}^{-1}$. Measurements on at least five different specimen positions have been collected for each sample.

Scanning electron microscopy (SEM) imaging was performed by using an ESEM FEI QUANTA 200 microscope (Thermo Fisher Scientific, Waltham, MA, U.S.A.).

Microspheres and fibers diameter size distribution was determined using ImageJ software, equipped with Diameter J plug-in. ${ }^{40}$

Density measurements were performed by a Thermo Pycnomatic Helium Pycnometer (Pycnomatic ATC, Thermo Fisher Scientific, Waltham, MA, U.S.A.) using $99.99 \%$ pure helium. Measurements were repeated at least five times for each sample at $20{ }^{\circ} \mathrm{C}$. Formulation of each composite was obtained by calculating the filler content, according to eq 1

$$
x_{\mathrm{w}, \mathrm{GO}}=\frac{\rho_{\mathrm{GO}}\left(\frac{\rho_{\mathrm{PCL}}}{\rho_{\mathrm{c}}}-1\right)}{\rho_{\mathrm{PCL}}-\rho_{\mathrm{GO}}}
$$

where $x_{\mathrm{w}, \mathrm{GO}}$ is the weight fraction of GO in each structure, while $\rho_{\mathrm{PCL}}$, $\rho_{\mathrm{GO}}$, and $\rho_{\mathrm{c}}$ respectively indicate the skeletal density values of polymer, GO and of composite. Of course, volume fraction of GO $\left(x_{\mathrm{V}, \mathrm{GO}}\right)$ can be easily assessed once is known $x_{\mathrm{w}, \mathrm{GO}}$, by using eq 2

$$
x_{\mathrm{V}, \mathrm{GO}}=\frac{\left(\frac{x_{\mathrm{w}, \mathrm{GO}}}{\rho_{\mathrm{GO}}}\right)}{\left(\frac{1-x_{\mathrm{w}, \mathrm{GO}}}{\rho_{\mathrm{PCL}}}\right)+\left(\frac{x_{\mathrm{w}, \mathrm{GO}}}{\rho_{\mathrm{GO}}}\right)}
$$

In order to evaluate apparent density, samples were embedded into epoxy resin prior to helium pycnometric measurements. ${ }^{41}$ More details can be found in SI (Table S1).

Porosity of the samples was then calculated using eq 3

$$
\text { Porosity }(\%)=\left(1-\frac{\rho \mathrm{a}}{\rho}\right) \times 100
$$

where $\rho_{\mathrm{a}}$ and $\rho$ are, respectively, apparent and skeletal density.
Mechanical tests in compression mode were carried out by using a dynamometer (Instron 3365, U.K.) equipped with a $1 \mathrm{kN}$ load cell. Measurements were performed onto dry-formed cylindrical specimens having $D=4 \mathrm{~mm}$ and height $=5.5 \mathrm{~mm}$ until failure by imposing a uniform strain rate of $1 \mathrm{~mm} \mathrm{~min}{ }^{-1}$. Data were analyzed to determine elastic modulus in the linear region, calculated as the slope extrapolated at zero strain, and in the densification region, by measuring the slope of each stress-strain curve after necking.

Water contact angle (WCA) and diiodomethane contact angle (DCA) measurements were performed at room temperature by using an FTA 1000 (First Ten Ångstroms, U.K.) instrument. Four microliters of deionized water or diiodomethane were dropped onto the surface of each sample by way of an automatic liquid drop dosing system. Images of the drops onto the surface were acquired after $20 \mathrm{~s}$.

Phenol removal tests were performed as follows. Phenol (0.64 mmol) was dissolved in water $(1 \mathrm{~L})$. For each test, $50 \mathrm{~mL}$ of solution was poured into a flask and vigorously stirred; meanwhile $0.106 \mathrm{~g}$ of either PCL45/GO or PCL80/GO scaffolds was immersed, and the sorption capacity of samples was assessed by monitoring at predetermined time intervals the residual phenol concentration via UV-vis spectroscopy, carried out in a UV-vis Specord 252 spectrophotometer (Analytik Jena, Jena, Germany). Absorbance values of the characteristic phenol signal (centered at $271 \mathrm{~nm}$ ) were converted into concentrations by using a calibration line, opportunely constructed in the concentration range of $0-0.0150 \mathrm{mmol} / \mathrm{L}$ (see Figure S5, SI).

Sorption was evaluated according to the following equation

$$
\text { Sorption }(\%)=\left(\frac{C_{0}-C_{t}}{C_{0}}\right) \times 100
$$

The time-dependent sorption capacity of materials, $Q_{t}$, was evaluated by using the following eq 5

$$
Q_{\mathrm{t}}=\left(\frac{C_{0}-C_{\mathrm{t}}}{m_{\mathrm{GO}}}\right) V
$$

where $C_{0}$ and $C_{\mathrm{t}}$ are, respectively, the phenol concentrations at the beginning of the experiment and at the given time interval, $V$ is the volume of solution, whereas $m_{\mathrm{GO}}$ indicates the GO content in each scaffold, easily calculated once both the weight mass of the sample and $x_{\mathrm{w}, \mathrm{GO}}$ via pycnometric measurements are known (see eq 1 ). It is possible to define $Q_{e}$ as the maximum sorption capacity achieved at saturation.

Theoretical modeling of sorption kinetics was performed to get insight into adsorption mechanism and rates. Among the several models generally adopted, ${ }^{42}$ herein we report, for sake of brevity, only those which gave the best fitting results, that is, pseudo-second order and intraparticle diffusion models. These two models are clearly able to give, more than others, an effective interpretation of the experimental results. Their equations, respectively, indicated as eq 6 and eq 7 , are provided in Table 2.

Both models allow calculating $k$, the kinetics rate constant, by regression lines as indicated in the last column of Table 2 . After usage, scaffolds were regenerated in fresh water at $T=45^{\circ} \mathrm{C}$ for $1 \mathrm{~h}$.

Phenol recovery efficiency was calculated as the ratio between the mass of phenol delivered in the regeneration bath $\left(M_{\text {delivered }}\right)$ and that adsorbed during the previous sorption stage $\left(M_{\text {adsorbed }}\right)$, according to the following eq 8

Table 2. Kinetic Models, Equations, and Regression Methods for Determining Rate Constants $(k)$

$\begin{array}{cccc}\text { model } & \text { equation } & \text { regression methods } \\ \begin{array}{c}\text { pseudo-2nd } \\ \text { order }\end{array} & \frac{t}{Q_{\mathrm{t}}}=\frac{1}{k Q_{\mathrm{e}}^{2}}+\frac{1}{Q_{\mathrm{e}}} t & (6) & \begin{array}{c}\text { plot: } t / Q_{t} \text { vs } t \text { slope }=\frac{1}{Q_{\mathrm{e}}} \\ \text { intercept }=\frac{1}{k Q_{\mathrm{e}}^{2}}\end{array} \\ \begin{array}{c}\text { intraparticle } \\ \text { diffusion }\end{array} & Q_{\mathrm{t}}=k t^{0.5}+c \quad(7) & \begin{array}{c}\text { plot: } Q_{\mathrm{t}} \text { vs } \sqrt{t} \text { slope }=k ; \\ \text { intercept }=c\end{array}\end{array}$




$$
\text { Phenol recovery efficiency }(\%)=\frac{M_{\text {delivered }}}{M_{\text {adsorbed }}} \times 100
$$

Of course, with the volume of water used being constant for each stage, the mass ratio of eq 8 is equal to the ratio between the phenol concentration released in regeneration bath and that adsorbed in the previous sorption stage. Moreover, reusability of the scaffolds was assessed by calculating $Q_{e}$ values achieved after each regeneration cycle.

\section{RESULTS AND DISCUSSION}

Prior to electrospinning, the rheological behavior of PCL45 and PCL80 solutions was analyzed. In fact, at fixed polymer

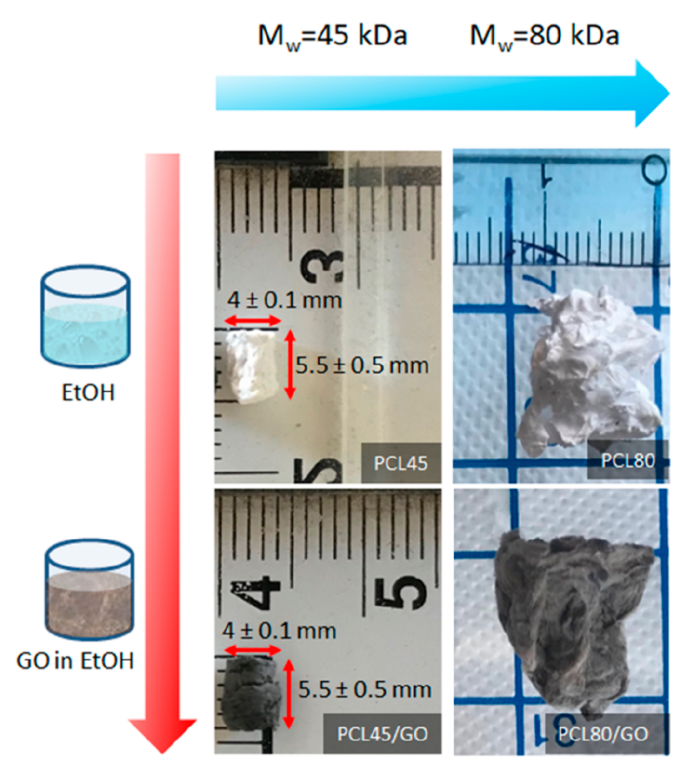

Figure 2. Digital photographs of macroscopic features of the four types of monoliths obtained by changing PCL $M_{w}$ and composition of liquid collector.
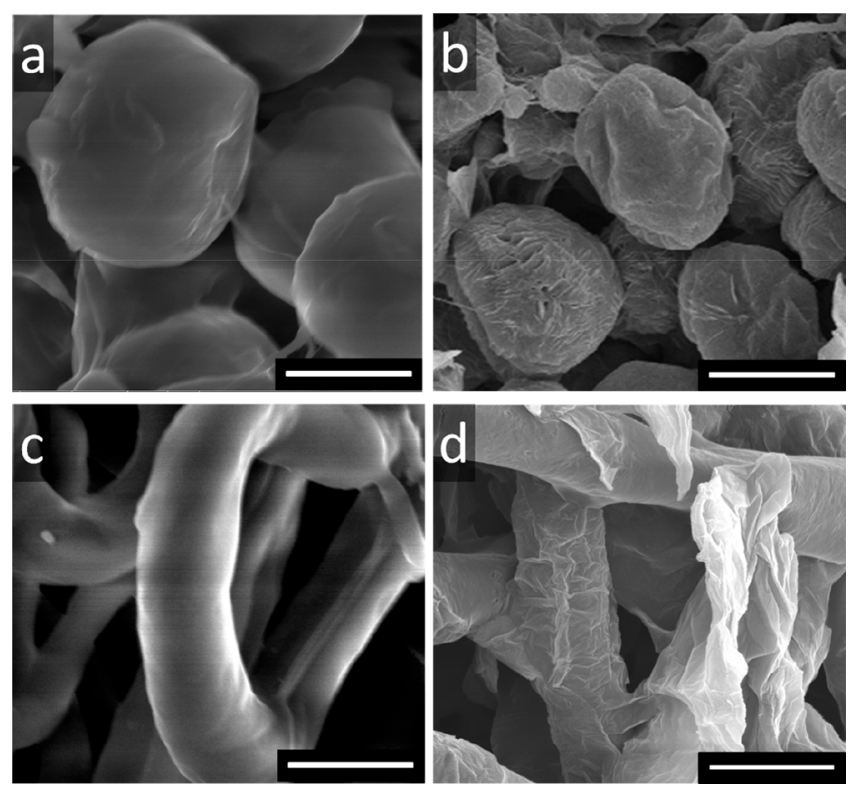

Figure 3. SEM micrographs of PCL45 (a), PCL45/GO (b), PCL80 (c), and PCL80/GO (d). Scale bars: $5 \mu \mathrm{m}$ for panels a,b, $3 \mu \mathrm{m}$ for panels c,d.
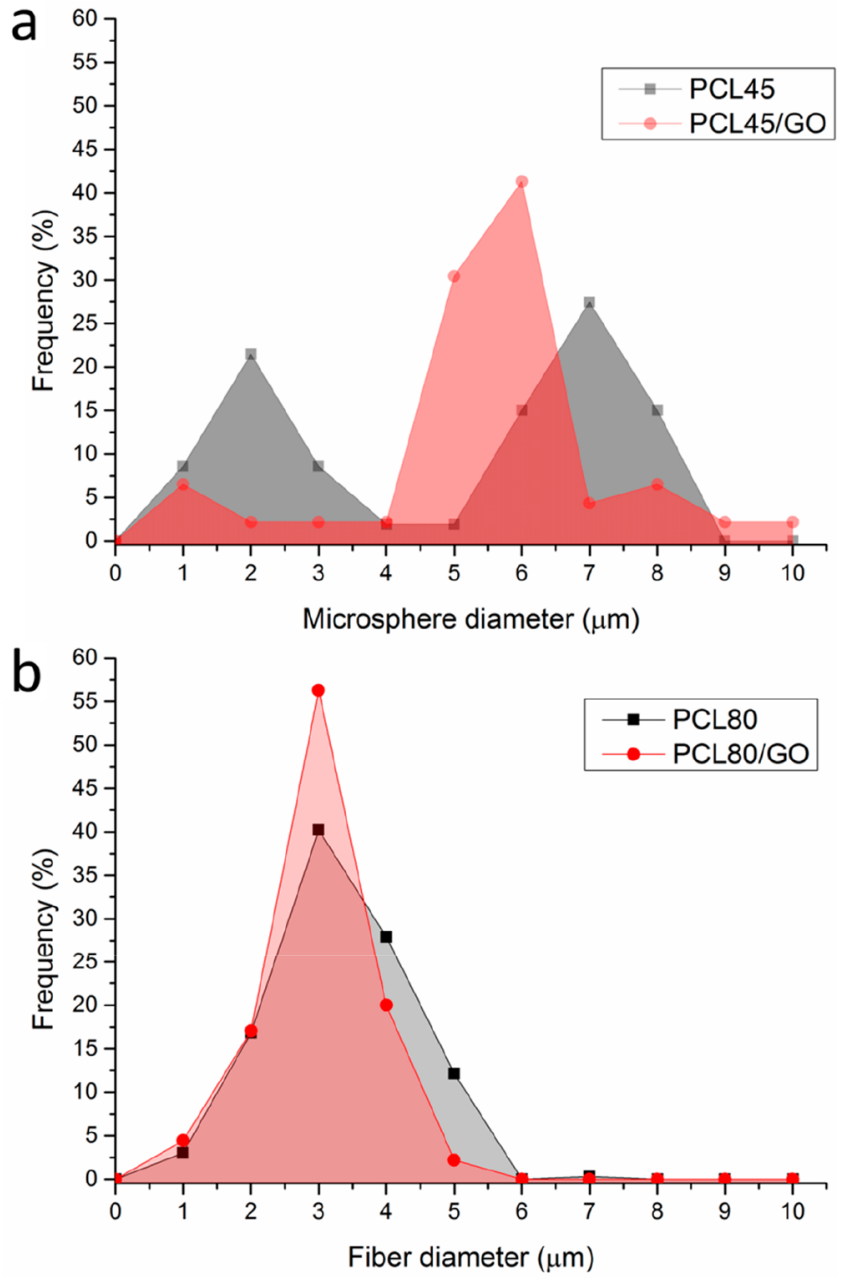

Figure 4. Microsphere diameter distribution of pearl necklace-like structures (a) and fiber diameter distribution of fluffy structures (b) achieved by Image Analysis.

Table 3. GO Content and Porosity of the Scaffolds Prepared

\begin{tabular}{llcc}
\multicolumn{1}{c}{ sample } & GO wt \% & GO vol \% & porosity (\%) \\
PCL45 & & & 95 \\
PCL80 & & & 98 \\
PCL45/GO & $10.15 \pm 3.3$ & $6.93 \pm 2.5$ & 92 \\
PCL80/GO & $29.7 \pm 0.5$ & $21.13 \pm 0.5$ & 96 \\
\hline
\end{tabular}

concentration (10 wt \%), solvent mixture composition (DCM/ EtOH 3:1 by volume) and supplied high voltage $(17 \mathrm{kV})$, having constant conductivity, the rheological behavior of polymer solutions is known to affect the electrospinnability of such systems, thus driving either electrospraying or electrospinning. In this sense, the molecular weight of PCL obviously influences the viscosity, which is known to increase upon increasing the molecular weight. Figure S6 provides the complex viscosity $\left(\eta^{*}\right)$ curves of the two solutions as a function of angular frequency $(\omega)$. As one can see, PCL45 displays a less remarkable non-Newtonian behavior with a viscosity scarcely dependent on angular frequency and ranging between 1 and $10 \mathrm{~Pa} \cdot \mathrm{s}$. By contrast, PCL80 solution exhibits a more remarkable non-Newtonian behavior, together with a complex viscosity up to 4 orders of magnitude higher. The differences observed in terms of shear viscosity suggest a different number of entanglements per chain, ${ }^{43}$ crucial to affect 

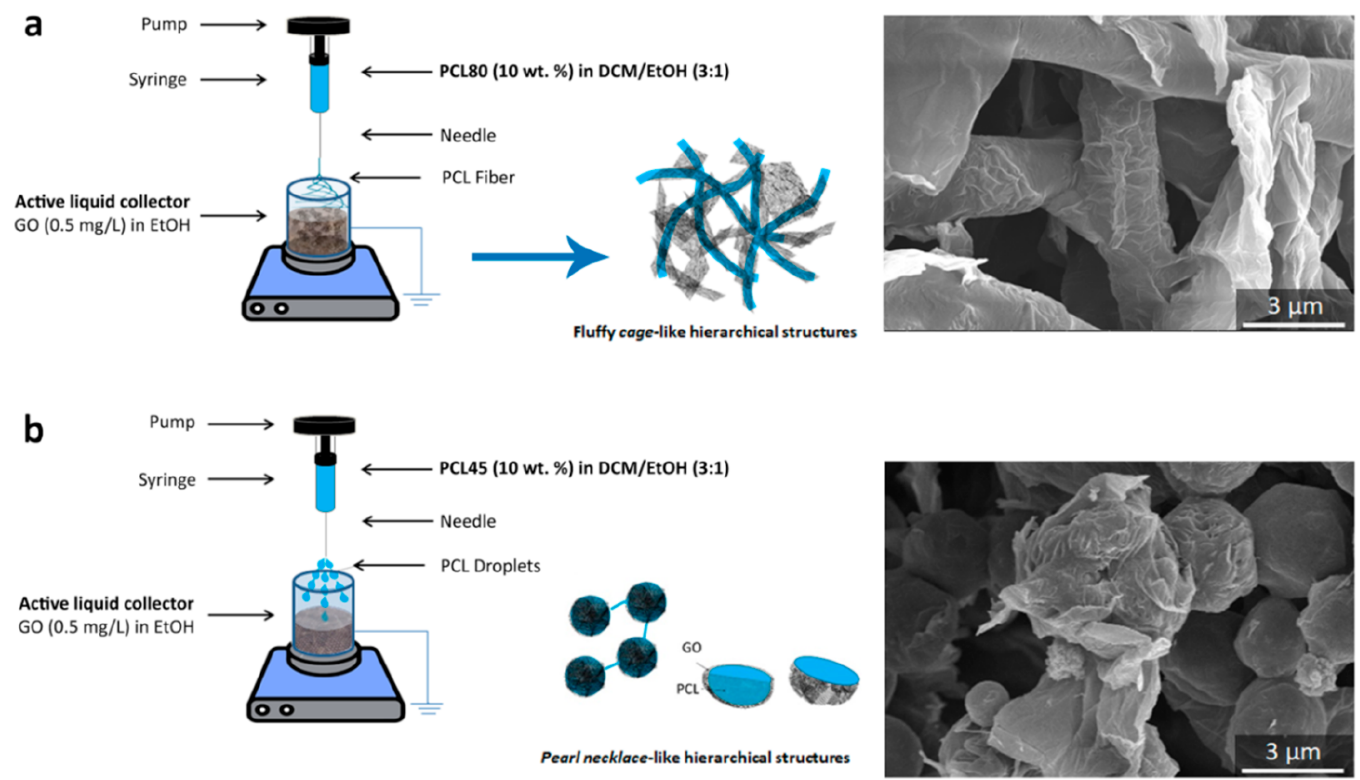

Figure 5. Pictorial representation of the processing-structure relationship together with SEM micrographs describing the surface texture of GOcoated PCL80 (a) and PCL45 (b).

or stabilize fiber formation. ${ }^{43}$ During the electroprocessing of polymer solutions, upon increasing polymer concentration a progressive change of fiber morphology is generally observed, which gradually turns from beads to fibers. Fundamentally, electrospraying and electrospinning of polymer solutions are substantially identical processes. According to the universal model proposed by Shenoy et al., ${ }^{43}$ it is possible to predict the morphology of a given electrospun structure, once polymer molecular weight and concentration of the corresponding solutions are known. Of course, in the case of dry jet-wet electrospinning, the $3 \mathrm{D}$ arrangement and the ultimate structure of the materials depend on other key-variables, including surface tension of coagulation bath, as well as its affinity to both polymer and solvents ejected from the syringe. Previous studies report that it is possible to obtain fluffy PCL scaffolds by optimum setting of the overall collecting distance, given by the sum of dry jet height and liquid height, which univocally determines the decay of electric field. ${ }^{38}$ Therefore, the possibility to design a priori two well-orchestrated polymeric structures and to provide them with a GO coating via a onepot strategy skin was elucidated. On the basis of these considerations, two samples of PCL having $M_{\mathrm{w}}$ equal to 45 and $80 \mathrm{kDa}$ were used in order to create two different 3D structures that usually attain enormous interest. In fact, PCL microspheres, for instance, are commonly used in biomedicine for encapsulating drugs and cell differentiation due to their good interaction with body microenvironment. ${ }^{44,45}$ Fluffy scaffolds, on the other hand, are suitable for tissue engineering, relying on a more extended surface area if compared to their $2 \mathrm{D}$ counterpart. ${ }^{41,45}$

Figure 2 provides digital photographs of the samples prepared in this work. It is worth noting that the materials containing PCL45 were dry-formed into cylinders, as they tend to remain somehow incoherent. Instead, PCL80-series materials can be obtained either as fluffy scaffolds or dryformed into cylinders (but even other shapes). The typical preparation of a PCL80/GO scaffold is provided in Video S1 (SI).
Figure 3 reports SEM micrographs of PCL45, PCL45/GO, PCL80, and PCL80/GO. When PCL45 was used, electrospraying phenomena prevail, thus leading to bead formation. Using ethanol bath as a liquid collector enables the formation of 3D structures arranged into a densely packed, pearl necklace-like configuration. In the case of PCL80, fibers only are formed; however, the typical 2D fibrous mat, usually obtainable by using either solid collectors or floating collectors, in this case evolves into a 3D fibrous fluffy scaffold due to the capability of the fibers to sink in a coagulation bath. Notably, the presence of GO lamellae dispersed in the liquid collector enables the uniform coating of such structures with this issue being likely due to the peculiar nature of GO, whose affinity to broad-spectrum moieties is well-known.

Image analysis was carried out to examine the diameter distributions of either PCL microspheres or fibers in the presence or absence of GO. In fact, the presence of GO in the coagulation bath may have two opposite repercussions on size distribution. On one hand, the formation of a GO shell is supposed to cause an obvious thickening of fibers and microspheres. On the other hand, it is worth considering that the coagulation bath containing GO has an electrical conductivity 30 times higher than that of pure ethanol with this aspect resulting in narrower distributions and size reduction.

PCL45 displays microspheres linked to each other by extremely thin fibers. The diameter size distribution of such spheres (Figure 4a) presents a bimodal, somehow broad distribution, whose maxima are centered at 2.5 and $7.5 \mu \mathrm{m}$.

In contrast, PCL45/GO shows a unimodal, narrower distribution with highly regular microspheres in which $72 \%$ display a diameter between 5 and $7 \mu \mathrm{m}$.

In fluffy fibrous structures, Figure $4 \mathrm{~b}$, both samples displayed unimodal distribution whose maxima were found to range between 3 and $4 \mu \mathrm{m}$. Although PCL80/GO exhibited size distribution narrower than PCL80, no size reduction was observed after GO-decoration. This feature could suggest that the formation of a thicker GO shell in PCL80/GO could have counterbalanced the shrinking effect imparted by the increased electrical conductivity. Hence, filler content in PCL45/GO and 


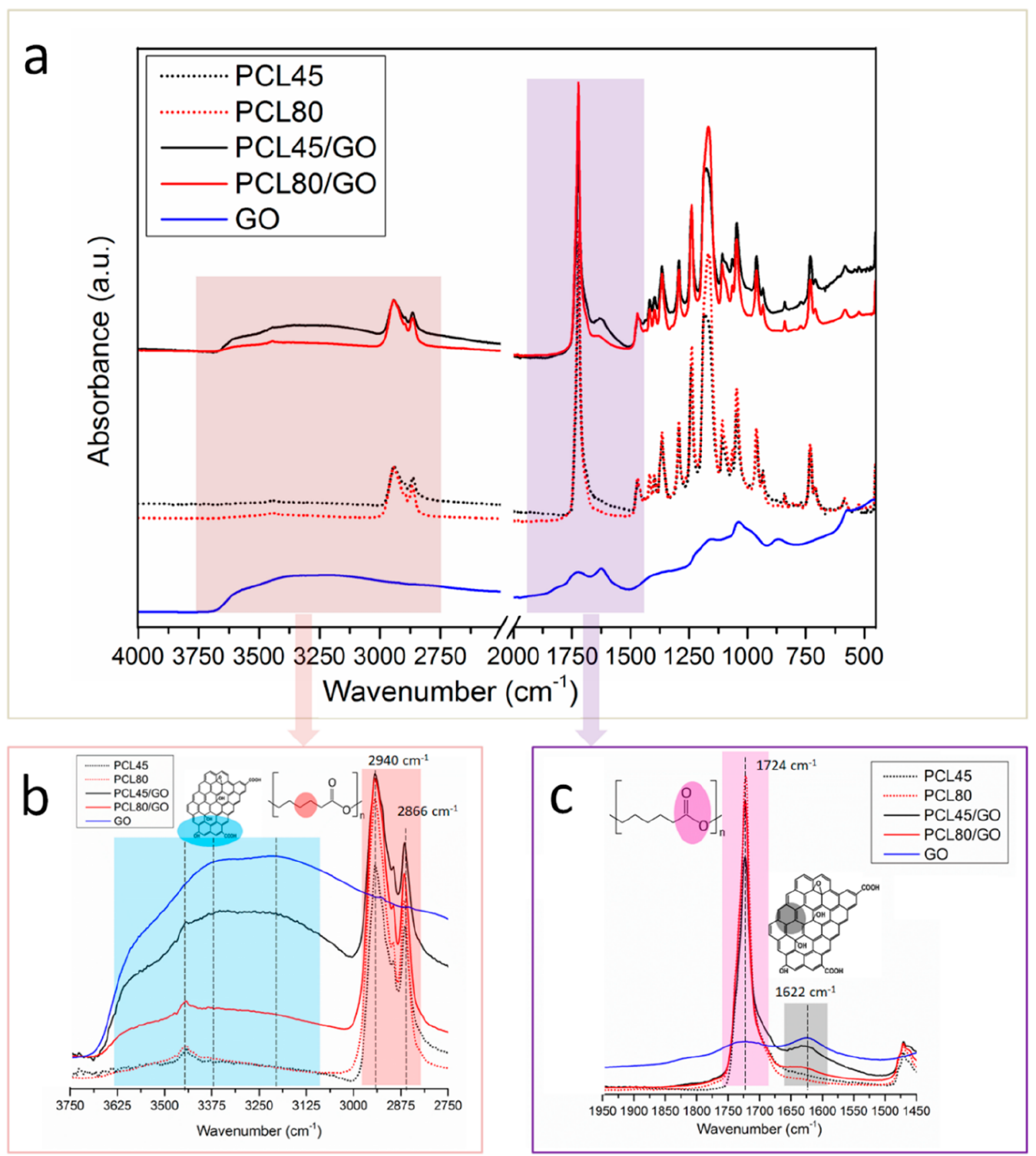

Figure 6. FTIR/ATR spectroscopic results of the five samples collected in the range $4000-450 \mathrm{~cm}^{-1}$ (a); enlargements of $3750-2750 \mathrm{~cm}^{-1}(\mathrm{~b})$ and $1950-1450 \mathrm{~cm}^{-1}$ region $(\mathrm{c})$.

PCL80/GO was evaluated by pycnometric density measurements, together with the porosity values of all the scaffolds, using eqs 1,2 , and 3 . The results, provided in Table 3 , reveal that the amount of GO in fluffy scaffolds (PCL80/GO) is three times larger than that of pearl necklace-like structures (PCL45/GO).

This aspect, in full agreement with what is hypothesized, is quite relevant since such a higher GO amount is extremely difficult to be incorporated into polymeric structures by adopting solvent- or melt-based common techniques.

The porosity levels attained make these 3D scaffolds intermediate between foams/sponges and aerogels. Obviously, fluffy structures display values of porosity higher than those of necklace pearl-like architectures.

Figure 5 illustrates the texture of fibrous PCL80 and PCL45 beads fully covered by GO lamellae (see the typical morphology of GO lamellae in SEM micrograph of Figure S4, SI). It is worth noting that GO-PCL interaction is durable even after 20 washing cycles in either water or oil (Figure S7, SI).
When a positively charged fiber or bead comes into contact with negatively charged GO lamellae, the former one is immediately enveloped by sheets, similarly to what is observed during wet spinning assembly of GO fibers. ${ }^{46}$

The method herein presented allows preserving the structure once it is formed while avoiding any further thermal or chemical treatment. Furthermore, it is possible to dry-form the materials into desired shapes (see Figure 2).

In order to investigate eventual changes in both PCL matrix and GO nanoparticles, spectroscopic analysis was performed on the prepared samples. FTIR/ATR spectra collected in the range $4000-400 \mathrm{~cm}^{-1}$ are reported in Figure $6 \mathrm{a}$, together with the close-up of two spectral regions of interest, that is, the ranges $3750-2750 \mathrm{~cm}^{-1}$ (Figure $6 \mathrm{~b}$ ) and $1950-1540 \mathrm{~cm}^{-1}$ (Figure 6c).

PCL45 and PCL80 spectra are practically identical and consistent with the scientific literature. ${ }^{47}$ Briefly, the infrared modes below $1000 \mathrm{~cm}^{-1}$ and those centered at 2846 and 2940 $\mathrm{cm}^{-1}$ are due to alkyl long chains, indicating rocking and vibration stretching of $-\mathrm{CH}_{2}-$ bonds, respectively. The ester 


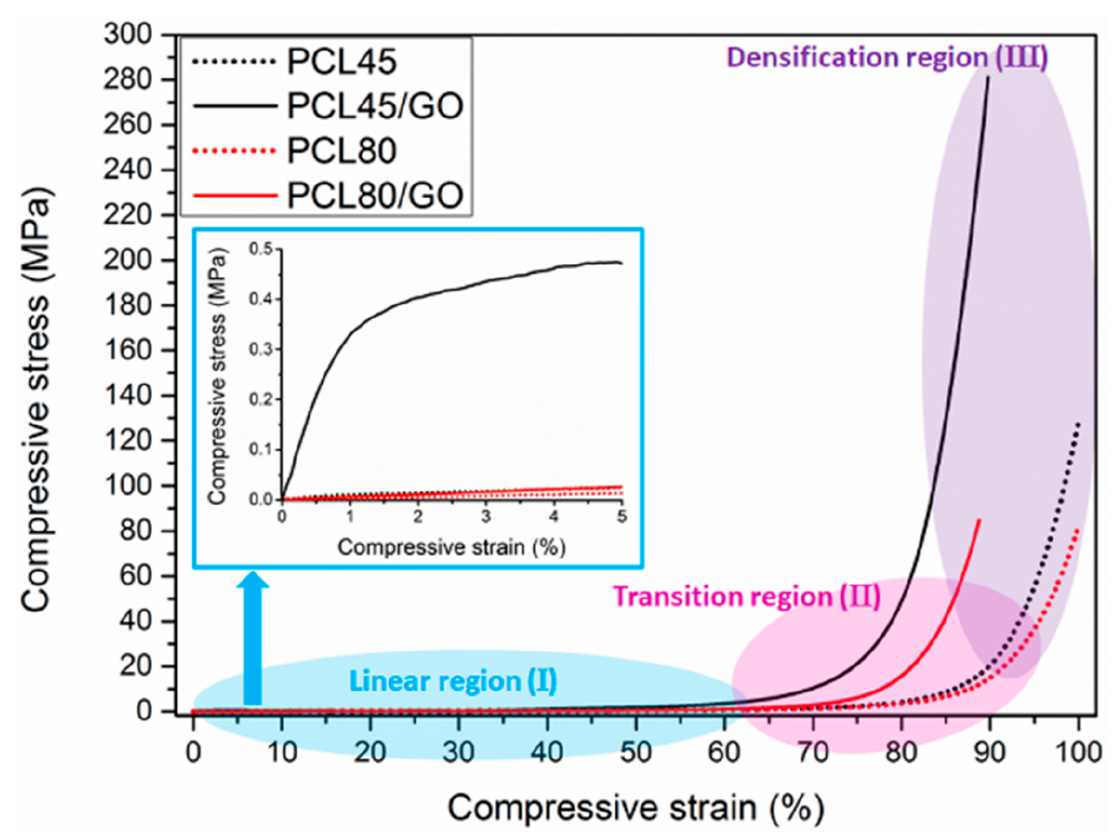

Figure 7. Typical stress-strain curves of the samples. Linear (i), transition (ii), and densification (iii) regions are evidenced. Inset: low-strain region to qualitatively assess elastic moduli.

Table 4. Main Mechanical Properties of the Samples Prepared $^{a}$

\begin{tabular}{lccccl}
\multicolumn{1}{c}{ sample } & $E_{\mathrm{i}}(\mathrm{MPa})$ & $E_{\mathrm{iii}}(\mathrm{MPa})$ & $E_{\mathrm{iii}} / E_{\mathrm{i}}$ & $E_{\mathrm{r}, \mathrm{i}}$ & $E_{\mathrm{r}, \text { iii }}$ \\
PCL45 & $1.06 \pm 0.0$ & $1126 \pm 14$ & 1062 & 1 & 1 \\
PCL80 & $0.16 \pm 0.0$ & $684 \pm 6$ & 4275 & 1 & 1 \\
PCL45/GO & $35 \pm 4$ & $2533 \pm 22$ & 61 & 33.02 & 1.89 \\
PCL80/GO & $2 \pm 0.3$ & $893 \pm 10$ & 447 & 12.5 & 1.31
\end{tabular}

${ }^{a}$ Elastic moduli in the linear (i) and densification (iii) regions, together with relative increments observed as an effect of densification $\left(E_{\mathrm{iii}} / E_{\mathrm{i}}\right)$ and reduced moduli $\left(E_{\mathrm{r}}\right)$ of composite scaffolds.

bonds are instead responsible for the presence of bands centered at $1190 \mathrm{~cm}^{-1}\left(\nu_{\mathrm{s}}(\mathrm{OC}-\mathrm{O})\right), 1246 \mathrm{~cm}^{-1}\left(\nu_{\text {as }}(\mathrm{C}-\right.$ $\mathrm{O}-\mathrm{C})), 1240 \mathrm{~cm}^{-1} \nu_{\mathrm{cr}}(\mathrm{C}-\mathrm{O})$, beyond the well-defined absorption peak located at $1724 \mathrm{~cm}^{-1}$.

Concerning GO, the broad absorption band in the 3750$2300 \mathrm{~cm}^{-1}$ region is traditionally assigned to $-\mathrm{OH}$ stretching due to phenols, carboxylic acids, and water. Two wellrecognizable bands are centered at around 1724 and 1622 $\mathrm{cm}^{-1}$ with the former being assigned to carbonyls or originating by bending modes of water molecules integrated into the GO structure, while the latter being ascribed to the aromatic sublattice of graphene oxide. At wavenumbers below $1250 \mathrm{~cm}^{-1}$, several overlapping signals are supposed to arise from $\mathrm{C}-\mathrm{O}-\mathrm{C}$ and $\mathrm{C}-\mathrm{OH}$ moieties under the form of either cyclic ethers or alcoholic groups.

After GO decoration, PCL80 and PCL45, while retaining all of their key infrared bands, present two additional features, that is, the typical mode centered at $1622 \mathrm{~cm}^{-1}$, ascribed to $\mathrm{C}=\mathrm{C}$ bond of graphenic lattice, together with the broad band at $3500-3000 \mathrm{~cm}^{-1}$ attributable to $\mathrm{O}-\mathrm{H}$ stretching. Notably, these graphenic signals proved to be much more intense in PCL45/GO microspheres. However, all the remaining GO bands were not detected, since PCL is reasonably more FTIRactive than GO. ${ }^{48}$

For a closer inspection of graphenic counterpart of such nanocomposites, Micro-Raman analysis was performed, owing to its high sensitiveness to carbonaceous materials. Figure S8a,b provides, respectively, $\mu$-Raman spectra of PCL45- and PCL80-series materials, together with that of GO as a reference.

PCL45 and PCL80 show the typical spectra of a semicrystalline polycaprolactone. ${ }^{49}$ Among others, the narrow band centered at $1109 \mathrm{~cm}^{-1}\left(\omega_{1}\right)$ is a vibration mode indicating $\mathrm{C}-$ C stretch, whereas $1723 \mathrm{~cm}^{-1}\left(\omega_{2}\right)$ refers to $\mathrm{C}=\mathrm{O}$ stretch, usually indicating dipole-dipole interactions in polyesters when $\mathrm{C}=\mathrm{O}$ groups are in close contact, that is, at distances below 4-5 A. The intense double-band at $2850-2950 \mathrm{~cm}^{-1}$ $\left(\omega_{5}-\omega_{6}\right)$ is related to $\mathrm{CH}_{2}$ stretching, similar to what is seen in FTIR analysis. In regard to GO, a systematic study and univocal attribution of micro-Raman modes for graphene oxides do not exist. In fact, the presence of wrinkles and surface defects in GO gives rise to the insurgence of multiple defect activated modes, which tend to merge together with the ensuing broadening of two main modes, that is, D-band, centered at $1350 \mathrm{~cm}^{-1}$, and $\mathrm{G}$ band at about $1600 \mathrm{~cm}^{-1}$. The former, close to the K-point in the Brillouin zone, is traditionally ascribed to the $\mathrm{sp}^{3}$ diamond-like carbons, whereas the latter (at point $\Gamma$ ) refers to the $\mathrm{sp}^{2}$ hybridized carbons. In the second order (two phonon) scattering (see spectral range within $2500-3500 \mathrm{~cm}^{-1}$ ), it can be recognized that two main features, that is, $2 \mathrm{D}$ mode $\left(2690 \mathrm{~cm}^{-1}\right)$, which is a secondorder overtone of a different in-plane vibration, and the $\mathrm{D}+\mathrm{G}$ band, centered at $2940 \mathrm{~cm}^{-1}$, result from the combination of D and G scattering peaks. ${ }^{36,50}$ At first glance, both GO-decorated PCL samples, despite their different structures, show spectra similar to that of pristine GO with the disappearance of most of the characteristic bands of PCL. Indeed, G-band is found to be unaltered, whereas D-band and second-order modes of GO proved to be shifted or to change in shape, intensity, and fwhm, thus suggesting that PCL-GO interactions involve the oxygenated sublattice of GO while preserving its graphenic domains. In regard to second-order modes, PCL45/GO displays higher intensity at $2950 \mathrm{~cm}^{-1}$, presumably indicating higher polymer concentration and a smoother signal, likely due 

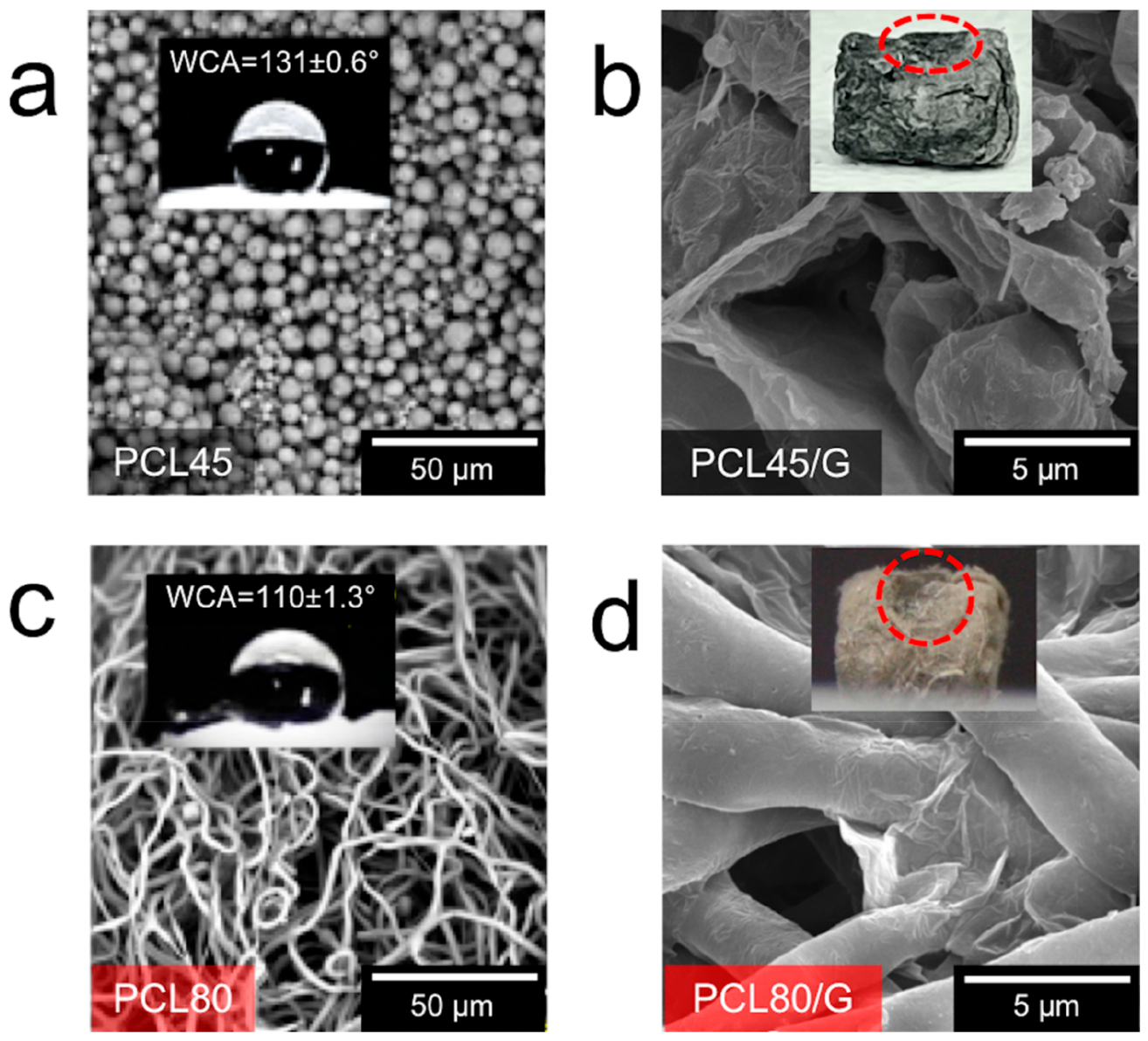

Figure 8. Wettability of the samples assessed via WCA measurements. The effect of microarchitecture results in a different WCA between PCL45 (a) and PCL80 (c). After GO-decoration, the surfaces of PCL45/GO (b) and PCL80/GO (d) become totally hydrophilic, regardless of template architecture. Color photographs are provided to easily recognize the areas wetted by water drops that instantly spread onto samples.

to a more regular structure. Notably, no emerging band was detected, in full agreement with the results of FTIR/ATR, thereby confirming that GO-decoration is mainly due to electrostatic interaction and wrapping.

The mechanical behavior of such systems was investigated by means of compressive tests. Figure 7 provides typical stress-strain curves of the samples, together with an enlargement of low-strain region provided in the inset of the same figure. For all of the materials, it is possible to detect three distinct zones: (i) linear region, (ii) transition region, and (iii) densification region, whose onset and extent depend on formulation. The linear region, see inset in Figure 7, is characterized by slow slopes of stress as a function of strain which arise from the collapse of voids in the porous structures. In this phase, the fibrous fluffs obviously showed the lowest values of elastic modulus $\left(E_{\mathrm{i}}\right)$ due to their obvious higher porosity degree and to the elastic buckling of the fibers constituting the cell ribs. Notably, PCL45/GO displayed $E_{\mathrm{i}}$ remarkably higher when compared with the other samples. The transition region is a nonlinear portion of stress-strain curves, characterized by the presence of necking, indicating the transition from an elastic to a plastic deformation. It is worth noting that even for the less deformable sample (PCL45/GO), necking was observed after $40 \%$ strain, while being detected at about $60-80 \%$ strain in the other materials. This aspect highlights the high flexibility of such structures. In the last region of the stress-strain curves, stress was found to increase linearly as a function of the strain. This feature can be ascribed to the densification phenomena occurring since the pore walls collapsed thus filling the voids.

The slope of the lines in densification region III was found to be remarkably higher than that observed in the linear zone I. Table 4 provides elastic moduli in the linear (i) and densification (iii) regions, together with relative increments observed as an effect of densification $\left(E_{\mathrm{iii}} / E_{\mathrm{i}}\right)$ for each sample, which are useful to assess the effect of architecture.

The reinforcing effect of GO coating was assessed by considering the reduced moduli $\left(E_{\mathrm{r}}\right)$, calculated as the ratio between the moduli of composites and those of the corresponding neat matrix (i.e., either PCL45 or PCL80) in both linear (subscript (i) and densification region (subscript (iii), also reported in Table 4.

It is well-known that mechanical performance is strictly dependent on different factors. Among the most influencing ones, molecular weight and morphology are definitely the most important.

Surprisingly, in the linear region PCL45 of lower molecular weight displays $E_{\mathrm{i}}$ about 7 times higher than that of PCL80 of higher molecular weight. Clearly, in this case morphology of the polymeric templates exerts an influence stronger than molecular weight with pearl necklace-like microstructure conferring denser structure, as already commented above. Furthermore, fluffy fibrous microstructure of PCL80 results in different mechanical solicitations, given the fact that thin fibers constituting cell ribs are prone to buckling during compression. 

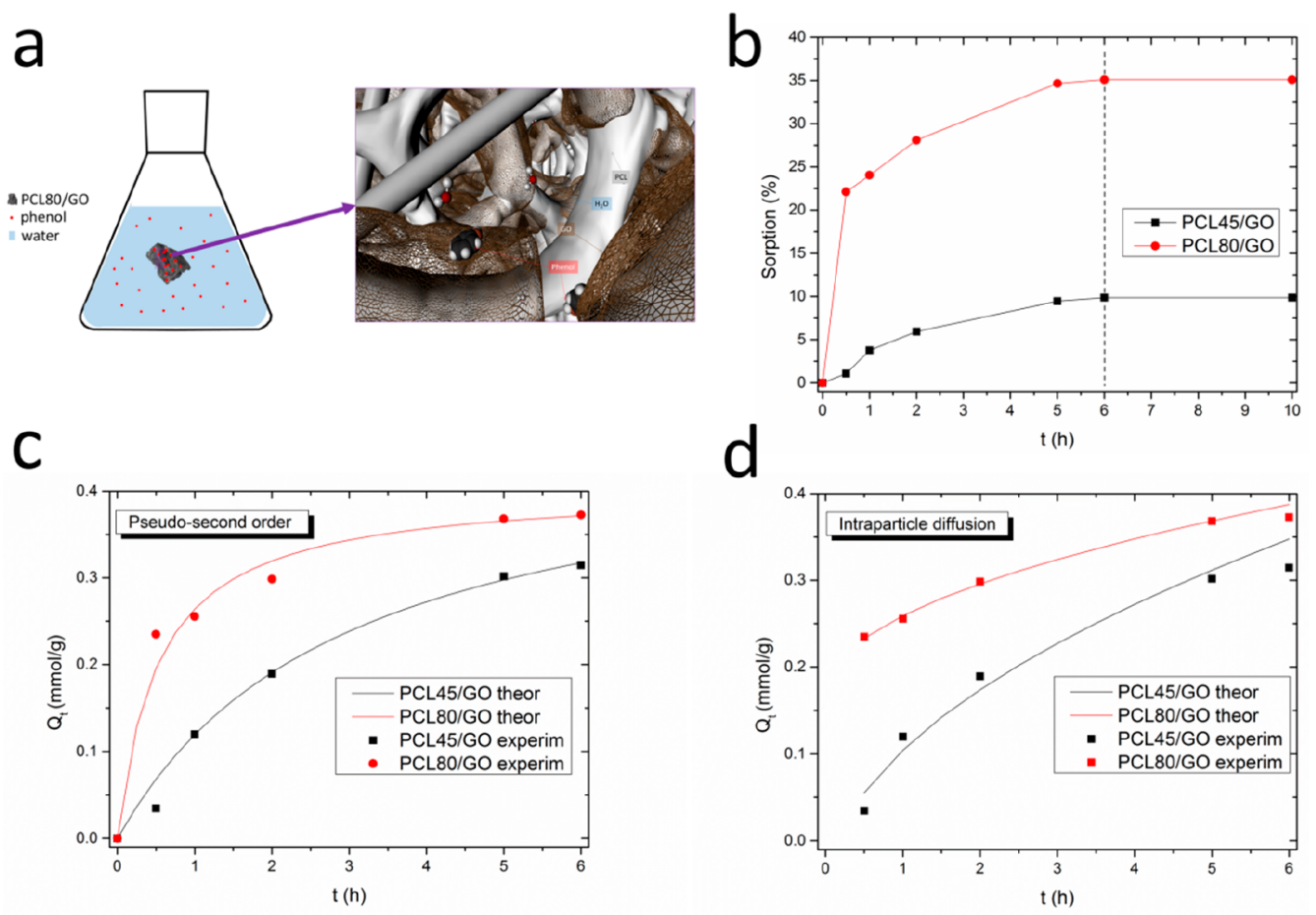

Figure 9. (a) Pictorial representation of the phenol absorption at a macro (left) and molecular (right) scale for a fluffy PCL80/GO scaffold. (b) Sorption percentage plotted as a function of time for PCL45/GO (squares) and PCL80/GO (circles); fitting of experimental data with (c) pseudosecond order model. (d) Intraparticle diffusion model.

Table 5. Fitting Results ${ }^{a}$

\begin{tabular}{clcccc}
\multicolumn{1}{c}{ model } & \multicolumn{1}{c}{ equation } & sample & $k(\mathrm{mmol} / \mathrm{g} / \mathrm{h})$ & $R^{2}$ \\
pseudo second order & $\frac{t}{Q_{\mathrm{t}}}=\frac{1}{k Q_{\mathrm{e}}^{2}}+\frac{1}{Q_{\mathrm{e}}} t$ & PCL45/GO & PCL80/GO & 4.6409 & 0.9989 \\
& $Q_{\mathrm{t}}=k t^{0.5}+c$ & PCL45/GO & 0.1677 & 0.9973 \\
intraparticle diffusion & & PCL80/GO & 0.0886 & 0.9737
\end{tabular}

${ }^{a} k$ and $R^{2}$ derived from pseudo-second order and diffusive models.

GO coating determines a drastic increment of the elastic modulus, more remarkable for PCL45/GO $\left(E_{\mathrm{r}, \mathrm{I}}=33.02\right)$ than for PCL80/GO $\left(E_{\mathrm{r}, \mathrm{i}}=12.5\right)$. This behavior can be explained again considering the peculiar morphology of the two samples. PCL45 materials display not only higher compactness when compared with PCL80 ones but also a template structured in microspheres that, covered with GO, are more able to effectively respond to compression and flexural solicitations during the test. In PCL80, the reinforcement effect is also visible but the higher porosity and the elongated shape of the fibers resulted in a worse performance.

In the densification region, the two structures tend to compact thus causing an increase of modulus for both samples, following the order PCL80 < PCL45 < PCL80/GO < PCL45/ GO. The differences among the samples are less remarkable, going from $684 \mathrm{MPa}$ of PCL80 to $2533 \mathrm{MPa}$ of PCL45/GO. During compaction, of course, the differences between the architectures of PCL45 and PCL80 progressively reduce, tending to a nonporous, dense structure. This occurrence is in full agreement with the mechanical results, also for PCL/GO systems; $E_{\mathrm{r}, \mathrm{iii}}$ is equal to 1.89 for PCL45/GO and 1.31 for PCL80/GO.
Beyond the differences observed, it can be concluded that GO-decoration endows such lightweight structures with a remarkable robustness and flexibility.

Of course, GO-decoration is supposed to change the wettability of PCL structures. In fact, GO is known to show high water affinity because of the abundance of oxygenated moieties onto its basal planes. ${ }^{51,52}$ WCA measurements, reported in Figure 8, put into evidence that PCL45 and PCL80 display a remarkable hydrophobic character because of the synergistic contribution of intrinsic hydrophobicity of PCL and surface texture.

In this context, we observed the highest hydrophobicity in PCL45 sample with WCA $=131 \pm 0.6^{\circ}$ due to the wellestablished lotus effect that is generally imparted by microspheres that act as microscale bumps. ${ }^{53,54}$ After GO-coating, both samples proved to be fully hydrophilic with WCA $=0^{\circ}$, and color photographs are reported aiming to recognize the portions of surface wetted by water droplets.

Notably, all of the samples displayed a total wettability in DCA testing (see Figure S9).

Even in this case, the color pictures were provided to put into evidence diiodomethane droplets totally spread onto the surface. GO-decoration endows these structures with a remarkable amphiphilicity with this feature being of enormous 


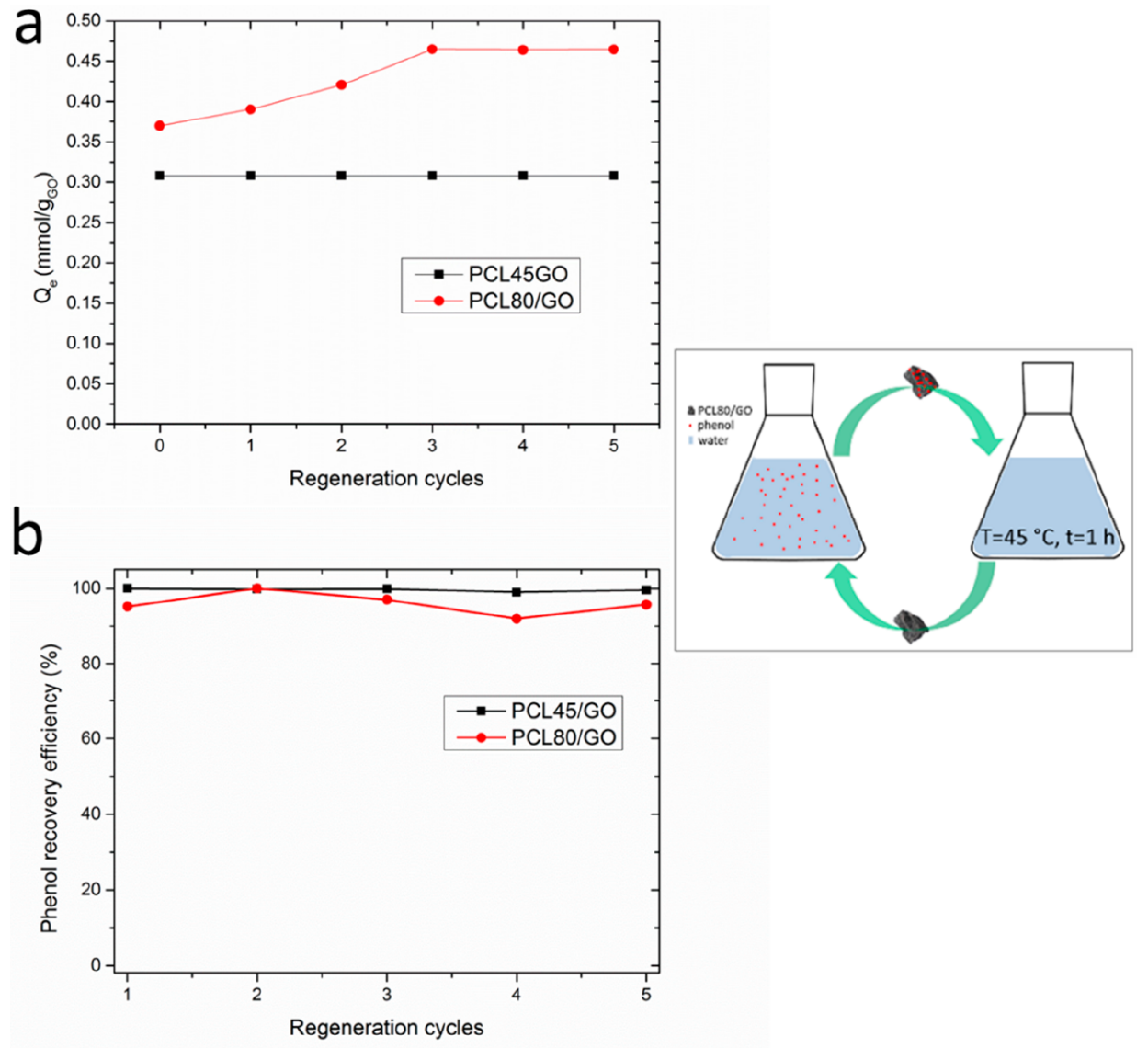

Figure 10. Reusability of scaffolds. Maximum sorption capacity (a) and phenol recovery efficiency (b) after five cycles together with pictorial representation of a regeneration cycle (right panel).

interest for realizing self-cleaning surfaces or for water treatment applications. In fact, such structures could be able to remove not only oil compounds, as generally observed for graphene-based and polymeric foams but even hydrosoluble pollutants, including phenolic compounds, dyes, and so on, relying on the high specific area imparted by the fabrication process and the chemical nature of GO.

As a potential application of these materials, we herein present the phenol sorption capacity of PCL45/GO and PCL80/GO scaffolds when immersed in a flask containing an aqueous solution of phenol $(60 \mathrm{mg} / \mathrm{L})$ at $\mathrm{pH}=7.5$.

A pictorial description of the generic experiment at macroand nanoscale is reported in Figure 9a.

Figure $9 \mathrm{~b}$ shows the behavior of sorption percentage as a function of time (see also UV-vis spectra collected for the phenol aqueous solutions treated with PCL45/GO and PCL80/GO at different time intervals, Figure S10).

Sorption kinetic tests pointed out that phenol sorption equilibrium is attained within $6 \mathrm{~h}$ with a rapid adsorption at the first $2 \mathrm{~h}$ followed by progressive slowdown of kinetics until plateauing. Relying on a higher specific surface and therefore higher GO content, PCL80/GO displayed 35\% sorption capacity, that is, 3.5 times higher than that of PCL45/GO and comparable with that of free nanoparticles of reduced GO at the same $\mathrm{pH}$ and initial concentration of phenol. ${ }^{55}$ Experimental data, normalized to the amount of GO (i.e., active compound) of each sample, were then analyzed by means of kinetic modeling in order to assess sorption rates and possible mechanisms. Generally speaking, sorption can be governed by surface adsorption, diffusivity or a combination of the two. ${ }^{56}$ The results, plotted in Figure $9 \mathrm{c}$ and listed in Table 5 , revealed that pseudo second order model allows the best data fitting $\left(R^{2}>0.997\right)$, thus indicating that the rate-limiting step is the surface adsorption, where the removal from solution is due to physicochemical interactions between the two phases. Intraparticle diffusion model was used too, and the results (see Figure $9 c$ and the last row of Table 5) pointed out that this model, characterized by diffusive rate-limiting step, allows a fairly good fitting for PCL80/GO only.

This feature could be reasonably explained by considering the different GO content in PCL45/GO (10 wt \%) and PCL80/GO (30 wt \%). In the latter structures, such a high GO amount inevitably results in remarkably thick lamellae stacking, which might have made it more difficult for phenol molecules to diffuse into the scaffolds. Moreover, it is obvious that materials having different morphologies may result in different sorption mechanisms.

Beyond the advantages of operating with a constant and a priori designable interface, integrating GO into a free-standing, green, and robust yet lightweight device enables easy recoverability of phenols and reusability of devices.

Such devices can be easily regenerated (see pictorial representation in Figure 10) via moderate thermal treatment at $T=45{ }^{\circ} \mathrm{C}$ for $1 \mathrm{~h}$ in fresh water, hence adopting milder conditions with respect to other regeneration methods proposed for desorbing phenols from graphene-coated polypyrrole fibers, which involve severe conditions $(T>220$ $\left.{ }^{\circ} \mathrm{C}\right){ }^{57}$ The reusability of such materials was assessed by 
evaluating eventual changes in both sorption capacity of the scaffolds and phenol recovery efficiency after each cycle, and the outcomes are shown in Figure 10a,b, respectively. The results highlighted that both systems retained their efficiency after five cycles. In more detail, PCL45/GO scaffolds, because of their compact structure, displayed a sorption capacity practically constant, whereas in PCL80/GO after an initial transition characterized by a progressive increase of their sorption capacity, $Q_{\mathrm{e}}$ flattened up to a value $25 \%$ higher than that of as prepared scaffolds (i.e., cycle 0 ).

Of course, the full reusability and facile dry-forming of such materials into desired shapes and dimensions may enable their use as filter cartridges in continuous separation or removal processes.

Ultimately, such lightweight yet strong, hierarchically structured materials possess all of the typical prerequisites of sorbent materials for wastewater treatment in terms of mechanical performance, surface wettability, and specific area. Moreover, they even showed excellent reusability, intended as retention of both sorption capacity and structural properties, and high efficiency in low energy recovery of phenol contaminants from aqueous solutions. All of these aspects fulfill the latest water treatment requirements in full compliance with the novel design guidelines inspired by circular economy and zero waste, thus paving the road for the realization of next generation materials for water technology. ${ }^{58}$

\section{CONCLUSIONS}

Two different polymer templates were prepared by dry jet-wet electrospraying or electrospinning two samples of PCL bearing different molecular weight onto an ethanol liquid collector. The suitable surface tension of EtOH allowed the polymer to sink, thus permitting the formation of $3 \mathrm{D}$ scaffolds. The different viscosity (and therefore entanglements) of PCL45 and PCL80 governed the microstructure, which proved to be arranged into a pearl necklace-like or fibrous configuration. Dispersing GO nanoparticles $(0.5 \mathrm{mg} / \mathrm{L})$ in an ethanol liquid collector enabled the possibility to perform a uniform, selfassembled GO-coating onto both types of polymeric architectures. The presence of a GO-shell imparted outstanding mechanical robustness and determined the creation of an amphiphilic surface, which was conveniently used to prepare reusable, green devices for removal of phenol contaminants from water. Preliminary tests highlighted that sorption kinetics follows a pseudo-second order mechanism and that the type of polymer template imparts significant differences in terms of sorption capacity and kinetic rate.

The outcomes of this work establish how the choice of the processing protocol can act as a crucial and tunable control parameter in the materials' design. Ultimately, the ability to endow different 3D architectures with a uniform coating of graphene oxide in such a rapid way is supposed to create a wealth of novel applications for a relatively well-known system, such as polycaprolactone-graphene oxide. On the other hand, the possibility to extend this processing pathway to other systems may open new scenarios for the fabrication of porous nanocomposites.

\section{ASSOCIATED CONTENT}

\section{(s) Supporting Information}

The Supporting Information is available free of charge at https://pubs.acs.org/doi/10.1021/acsapm.0c00852.
Further details on pycnometric measurements; data and results of Helium pycnometer measurements on samples embedded in epoxy resin; spectroscopic analysis of GO: XPS results, SEM micrograph, phenol calibration curve; complex viscosity of polymeric solutions; Raman analysis of scaffolds and raw materials; lipophilicity tests of scaffolds; UV-vis spectra of aqueous solutions of phenol treated with scaffolds at different time (PDF) Typical preparation of a PCL80/GO scaffold by dry jetwet-electrospinning and subsequent dry-forming (MPG)

\section{AUTHOR INFORMATION}

\section{Corresponding Author}

Roberto Scaffaro - Department of Engineering, University of Palermo, 90128 Palermo, Italy; 10 orcid.org/0000-0002-

4830-0374; Email: roberto.scaffaro@unipa.it

\author{
Authors \\ Andrea Maio - Department of Engineering, University of \\ Palermo, 90128 Palermo, Italy \\ Michele Gammino - Department of Engineering, University of \\ Palermo, 90128 Palermo, Italy \\ Emmanuel Fortunato Gulino - Department of Engineering, \\ University of Palermo, 90128 Palermo, Italy \\ Bartolomeo Megna - Department of Engineering, University of \\ Palermo, 90128 Palermo, Italy \\ Pierluca Fara - Department of Engineering, University of \\ Palermo, 90128 Palermo, Italy
}

Complete contact information is available at:

https://pubs.acs.org/10.1021/acsapm.0c00852

\section{Notes}

The authors declare no competing financial interest.

\section{ACKNOWLEDGMENTS}

Work fully supported by PO-FESR-2014-2020-SICILIA, SAWE, “Support, Alerting, Early Warning” cod. no. 08PA9511000101 CUP G78I18000960007 Azione 1.1.5 Regione Siciliana

\section{REFERENCES}

(1) Zhou, F.-L.; Wu, H.; McHugh, D. J.; Wimpenny, I.; Zhang, X.; Gough, J. E.; Hubbard Cristinacce, P. L.; Parker, G. J.M. CoElectrospraying of Tumour Cell Mimicking Hollow Polymeric Microspheres for Diffusion Magnetic Resonance Imaging. Mater. Sci. Eng., C 2019, 101, 217-227.

(2) Sitt, A.; Soukupova, J.; Miller, D.; Verdi, D.; Zboril, R.; Hess, H.; Lahann, J. Microscale Rockets and Picoliter Containers Engineered from Electrospun Polymeric Microtubes. Small 2016, 12 (11), 14321439.

(3) Davoodi, P.; Feng, F.; Xu, Q.; Yan, W.-C.; Tong, Y. W.; Srinivasan, M. P.; Sharma, V. K.; Wang, C.-H. Coaxial Electrohydrodynamic Atomization: Microparticles for Drug Delivery Applications. J. Controlled Release 2015, 205, 70-82.

(4) Alenezi, H.; Cam, M. E.; Edirisinghe, M. Experimental and Theoretical Investigation of the Fluid Behavior during Polymeric Fiber Formation with and without Pressure. Appl. Phys. Rev. 2019, 6 (4), 041401.

(5) Li, W.; Wang, H.; Li, Z. Preparation of Golf Ball-Shaped Microspheres with Fluorinated Polycaprolactone via Single-Solvent Electrospraying for Superhydrophobic Coatings. Prog. Org. Coat. 2019, 131, 276-284.

(6) Cao, C.-F.; Zhang, G.-D.; Zhao, L.; Gong, L.-X.; Gao, J.-F.; Jiang, J.-X.; Tang, L.-C.; Mai, Y.-W. Design of Mechanically Stable, 
Electrically Conductive and Highly Hydrophobic Three-Dimensional Graphene Nanoribbon Composites by Modulating the Interconnected Network on Polymer Foam Skeleton. Compos. Sci. Technol. 2019, 171, 162-170.

(7) Scaffaro, R.; Maio, A.; Lopresti, F.; Botta, L. Nanocarbons in Electrospun Polymeric Nanomats for Tissue Engineering: A Review. Polymers (Basel, Switz.) 2017, 9 (2), 76.

(8) Scaffaro, R.; Maio, A.; Lo Re, G.; Parisi, A.; Busacca, A. Advanced Piezoresistive Sensor Achieved by Amphiphilic Nanointerfaces of Graphene Oxide and Biodegradable Polymer Blends. Compos. Sci. Technol. 2018, 156, 166-176.

(9) Scaffaro, R.; Maio, A. Influence of Oxidation Level of Graphene Oxide on the Mechanical Performance and Photo-Oxidation Resistance of a Polyamide 6. Polymers (Basel, Switz.) 2019, 11 (5), 857.

(10) Adamu, H.; Dubey, P.; Anderson, J. A. Probing the Role of Thermally Reduced Graphene Oxide in Enhancing Performance of $\mathrm{TiO} 2$ in Photocatalytic Phenol Removal from Aqueous Environments. Chem. Eng. J. 2016, 284, 380-388.

(11) Yang, S.; Cui, Y.; Sun, Y.; Yang, H. Graphene Oxide as an Effective Catalyst for Wet Air Oxidation of Phenol. J. Hazard. Mater. 2014, 280, 55-62.

(12) Matharu, R. K.; Tabish, T. A.; Trakoolwilaiwan, T.; Mansfield, J.; Moger, J.; Wu, T.; Lourenço, C.; Chen, B.; Ciric, L.; Parkin, I. P.; Edirisinghe, M. Microstructure and Antibacterial Efficacy of Graphene Oxide Nanocomposite Fibres. J. Colloid Interface Sci. 2020, 571, 239252.

(13) Compton, O. C.; Nguyen, S. T. Graphene Oxide, Highly Reduced Graphene Oxide, and Graphene: Versatile Building Blocks for Carbon-Based Materials. Small 2010, 6 (6), 711-723.

(14) Maio, A.; Scaffaro, R.; Lentini, L.; Palumbo Piccionello, A.; Pibiri, I. Perfluorocarbons-graphene Oxide Nanoplatforms as Biocompatible Oxygen Reservoirs. Chem. Eng. J. 2018, 334, 54-65.

(15) Morimoto, N.; Suzuki, H.; Takeuchi, Y.; Kawaguchi, S.; Kunisu, M.; Bielawski, C. W.; Nishina, Y. Real-Time, in Situ Monitoring of the Oxidation of Graphite: Lessons Learned. Chem. Mater. 2017, 29 (5), 2150-2156.

(16) Liu, C.; Wong, H. M.; Yeung, K. W. K.; Tjong, S. C. Novel Electrospun Polylactic Acid Nanocomposite Fiber Mats with Hybrid Graphene Oxide and Nanohydroxyapatite Reinforcements Having Enhanced Biocompatibility. Polymers (Basel, Switz.) 2016, 8 (8), 287.

(17) Ceretti, E.; Ginestra, P. S.; Ghazinejad, M.; Fiorentino, A.; Madou, M. Electrospinning and Characterization of Polymergraphene Powder Scaffolds. CIRP Ann. 2017, 66 (1), 233-236.

(18) Wan, C.; Chen, B. Poly $(\varepsilon$-Caprolactone $) /$ graphene Oxide Biocomposites: Mechanical Properties and Bioactivity. Biomed. Mater. 2011, 6 (5), 055010.

(19) Aznar-cervantes, S.; Martínez, J. G.; Bernabeu-esclapez, A.; Lozano-pérez, A. A.; Meseguer-olmo, L.; Otero, T. F.; Cenis, J. L. Bioelectrochemistry Fabrication of Electrospun Silk Fi Broin Scaffolds Coated with Graphene Oxide and Reduced Graphene for Applications in Biomedicine. Bioelectrochemistry 2016, 108, 36-45.

(20) Melucci, M.; Kovtun, A.; Bianchi, A.; Zambianchi, M.; Bettini, C.; Ruani, G.; Corticelli, F.; Bocchi, L.; Stante, F.; Gazzano, M.; Marforio, T. D.; Calvaresi, M.; Minelli, M.; Navacchia, M. L.; Palermo, V. Core-Shell Graphene Oxide-Polymer Hollow Fibers as Water Filters with Enhanced Performance and Selectivity. Faraday Discuss. DOI: 10.1039/C9FD00117D.

(21) Cheng, Y.; Wang, R.; Sun, J.; Gao, L. A Stretchable and Highly Sensitive Graphene-Based Fiber for Sensing Tensile Strain, Bending, and Torsion. Adv. Mater. 2015, 27 (45), 7365-7371.

(22) Lu, Z.; Foroughi, J.; Wang, C.; Long, H.; Wallace, G. G. Superelastic Hybrid CNT/Graphene Fibers for Wearable Energy Storage. Adv. Energy Mater. 2018, 8 (8), 1702047.

(23) Jiang, X.; Ren, Z.; Fu, Y.; Liu, Y.; Zou, R.; Ji, G.; Ning, H.; Li, Y.; Wen, J.; Qi, H. J.; Xu, C.; Fu, S.; Qiu, J.; Hu, N. Highly Compressible and Sensitive Pressure Sensor under Large Strain Based on 3D Porous Reduced Graphene Oxide Fiber Fabrics in Wide
Compression Strains. ACS Appl. Mater. Interfaces 2019, 11 (40), 37051-37059.

(24) Zhang, G.; Wang, P.; Zhang, X.; Xiang, C.; Li, L. Preparation of Hierarchically Structured PCL Superhydrophobic Membrane via Alternate Electrospinning/electrospraying Techniques. J. Polym. Sci., Part B: Polym. Phys. 2019, 57 (8), 421-430.

(25) Malikmammadov, E.; Tanir, T. E.; Kiziltay, A.; Hasirci, V.; Hasirci, N. PCL and PCL-Based Materials in Biomedical Applications. J. Biomater. Sci., Polym. Ed. 2018, 29 (7-9), 863-893.

(26) Woodruff, M. A.; Hutmacher, D. W. The Return of a Forgotten polymer-Polycaprolactone in the 21st Century. Prog. Polym. Sci. 2010, 35 (10), 1217-1256.

(27) Scaffaro, R.; Maio, A.; Sutera, F.; Gulino, E. F.; Morreale, M. Degradation and Recycling of Films Based on Biodegradable Polymers: A Short Review. Polymers (Basel, Switz.) 2019, 11 (4), 651.

(28) Lee, A.; Elam, J. W.; Darling, S. B. Membrane Materials for Water Purification: Design, Development, and Application. Environ. Sci. Water Res. Technol. 2016, 2 (1), 17-42.

(29) Ramírez, E. E. P.; de la Luz Asunción, M.; Rivalcoba, V. S.; Hernández, A. L. M.; Santos, C. V. Removal of Phenolic Compounds from Water by Adsorption and Photocatalysis. In Phenolic Compounds; Soto-Hernandez, M., Palma-Tenango, M., del Rosario Garcia-Mateos, M., Eds.; IntechOpen: Rijeka, 2017; pp 343-372.

(30) Ferri, M.; Vannini, M.; Ehrnell, M.; Eliasson, L.; Xanthakis, E.; Monari, S.; Sisti, L.; Marchese, P.; Celli, A.; Tassoni, A. From Winery Waste to Bioactive Compounds and New Polymeric Biocomposites: A Contribution to the Circular Economy Concept. J. Adv. Res. 2020, 24, $1-11$.

(31) Pérez-Ramírez, E. E.; de la Luz-Asunción, M.; MartínezHernández, A. L.; Velasco-Santos, C. Graphene Materials to Remove Organic Pollutants and Heavy Metals from Water: Photocatalysis and Adsorption. In Semiconductor Photocatalysis - Materials, Mechanisms and Applications; 2016; pp 491-522.

(32) Marcano, D. C.; Kosynkin, D. V.; Berlin, J. M.; Sinitskii, A.; Sun, Z.; Slesarev, A.; Alemany, L. B.; Lu, W.; Tour, J. M. Improved Synthesis of Graphene Oxide. ACS Nano 2010, 4 (8), 4806-4814.

(33) Maio, A.; Giallombardo, D.; Scaffaro, R.; Palumbo Piccionello, A.; Pibiri, I. Synthesis of a Fluorinated Graphene Oxide-Silica Nanohybrid: Improving Oxygen Affinity. RSC Adv. 2016, 6 (52), 46037-46047.

(34) Scaffaro, R.; Maio, A.; Lopresti, F.; Giallombardo, D.; Botta, L.; Bondì, M. L.; Agnello, S. Synthesis and Self-Assembly of a PEGylatedGraphene Aerogel. Compos. Sci. Technol. 2016, 128, 193-200.

(35) Scaffaro, R.; Lopresti, F.; Maio, A.; Botta, L.; Rigogliuso, S.; Ghersi, G. Electrospun PCL/GO-G-PEG Structures: ProcessingMorphology-Properties Relationships. Composites, Part A 2017, 92, 97-107.

(36) Maio, A.; Agnello, S.; Khatibi, R.; Botta, L.; Alessi, A.; Piazza, A.; Buscarino, G.; Mezzi, A.; Pantaleo, G.; Scaffaro, R. A Rapid and Eco-Friendly Route to Synthesize Graphene-Doped Silica Nanohybrids. J. Alloys Compd. 2016, 664, 428-438.

(37) Li, H.; Zhang, W.; Ding, Q.; Jin, X.; Ke, Q.; Li, Z.; Wang, D.; Huang, C. Facile Strategy for Fabrication of Flexible, Breathable, and Washable Piezoelectric Sensors via Welding of Nanofibers with Multiwalled Carbon Nanotubes (MWCNTs). ACS Appl. Mater. Interfaces 2019, 11 (41), 38023-38030.

(38) Kostakova, E.; Seps, M.; Pokorny, P.; Lukas, D. Study of Polycaprolactone Wet Electrospinning Process. eXPRESS Polym. Lett. 2014, 8 (8), 554-564.

(39) Chandran, S.; Baschnagel, J.; Cangialosi, D.; Fukao, K.; Glynos, E.; Janssen, L. M. C.; Müller, M.; Muthukumar, M.; Steiner, U.; Xu, J.; Napolitano, S.; Reiter, G. Processing Pathways Decide Polymer Properties at the Molecular Level. Macromolecules 2019, 52 (19), $7146-7156$

(40) Hotaling, N. A.; Bharti, K.; Kriel, H.; Simon, C. G. DiameterJ: A Validated Open Source Nanofiber Diameter Measurement Tool. Biomaterials 2015, 61, 327-338.

(41) Jing, X.; Li, H.; Mi, H.-Y.; Liu, Y.-J.; Tan, Y.-M. Fabrication of Three-Dimensional Fluffy Nanofibrous Scaffolds for Tissue Engineer- 
ing via Electrospinning and $\mathrm{CO} 2$ Escaping Foaming. Ind. Eng. Chem. Res. 2019, 58 (22), 9412-9421.

(42) Ho, Y.-S. Review of Second-Order Models for Adsorption Systems. J. Hazard. Mater. 2006, 136 (3), 681-689.

(43) Shenoy, S. L.; Bates, W. D.; Frisch, H. L.; Wnek, G. E. Role of Chain Entanglements on Fiber Formation during Electrospinning of Polymer Solutions: Good Solvent, Non-Specific Polymer-Polymer Interaction Limit. Polymer 2005, 46 (10), 3372-3384.

(44) Huang, X.; Gao, J.; Li, W.; Xue, H.; Li, R. K. Y.; Mai, Y.-W. Preparation of Poly $(\varepsilon$-Caprolactone) Microspheres and Fibers with Controllable Surface Morphology. Mater. Des. 2017, 117, 298-304.

(45) Khoshroo, K.; Jafarzadeh Kashi, T. S.; Moztarzadeh, F.; Tahriri, M.; Jazayeri, H. E.; Tayebi, L. Development of 3D PCL microsphere/ $\mathrm{TiO} 2$ Nanotube Composite Scaffolds for Bone Tissue Engineering. Mater. Sci. Eng., C 2017, 70, 586-598.

(46) Cong, H.-P.; Ren, X.-C.; Wang, P.; Yu, S.-H. Wet-Spinning Assembly of Continuous, Neat, and Macroscopic Graphene Fibers. Sci. Rep. 2012, 2, 613.

(47) Krzaczkowska, J.; Fojud, Z.; Kozak, M.; Jurga, S. Spectroscopic Studies of $\operatorname{Poly}(\varepsilon$-Caprolactone $) /$ sodium Montmorillonite Nanocomposites. Acta Phys. Pol., A 2005, 108 (1), 187-196.

(48) Lipovka, A.; Rodriguez, R.; Bolbasov, E.; Maryin, P.; Tverdokhlebov, S.; Sheremet, E. Time-Stable Wetting Effect of Plasma-Treated Biodegradable Scaffolds Functionalized with Graphene Oxide. Surf. Coat. Technol. 2020, 388, 125560.

(49) Kotula, A. P.; Snyder, C. R.; Migler, K. B. Determining Conformational Order and Crystallinity in Polycaprolactone via Raman Spectroscopy. Polymer 2017, 117, 1-10.

(50) Agnello, S.; Alessi, A.; Buscarino, G.; Piazza, A.; Maio, A.; Botta, L.; Scaffaro, R. Structural and Thermal Stability of Graphene Oxide-Silica Nanoparticles Nanocomposites. J. Alloys Compd. 2017, 695, 2054-2064.

(51) Wu, T.; Zhou, B.; Zhu, T.; Shi, J.; Xu, Z.; Hu, C.; Wang, J. Facile and Low-Cost Approach towards a PVDF Ultrafiltration Membrane with Enhanced Hydrophilicity and Antifouling Performance via Graphene Oxide/water-Bath Coagulation. RSC Adv. 2015, 5 (11), 7880-7889.

(52) Wang, H.; Wang, W.; Wang, L.; Zhao, B.; Zhang, Z.; Xia, X.; Yang, H.; Xue, Y.; Chang, N. Enhancement of Hydrophilicity and the Resistance for Irreversible Fouling of Polysulfone (PSF) Membrane Immobilized with Graphene Oxide (GO) through Chloromethylated and Quaternized Reaction. Chem. Eng. J. 2018, 334, 2068-2078.

(53) Liu, Y.; Tang, J.; Wang, R.; Lu, H.; Li, L.; Kong, Y.; Qi, K.; Xin, J. H. Artificial Lotus Leaf Structures from Assembling Carbon Nanotubes and Their Applications in Hydrophobic Textiles. J. Mater. Chem. 2007, 17 (11), 1071-1078.

(54) Sun, M.; Luo, C.; Xu, L.; Ji, H.; Ouyang, Q.; Yu, D.; Chen, Y. Artificial Lotus Leaf by Nanocasting. Langmuir 2005, 21 (19), 89788981.

(55) Yu, S.; Wang, X.; Yao, W.; Wang, J.; Ji, Y.; Ai, Y.; Alsaedi, A.; Hayat, T.; Wang, X. Macroscopic, Spectroscopic, and Theoretical Investigation for the Interaction of Phenol and Naphthol on Reduced Graphene Oxide. Environ. Sci. Technol. 2017, 51 (6), 3278-3286.

(56) Robati, D. Pseudo-Second-Order Kinetic Equations for Modeling Adsorption Systems for Removal of Lead Ions Using Multi-Walled Carbon Nanotube. J. Nanostructure Chem. 2013, 3 (1), 55.

(57) Zou, J.; Song, X.; Ji, J.; Xu, W.; Chen, J.; Jiang, Y.; Wang, Y.; Chen, X. Polypyrrole/graphene Composite-Coated Fiber for the Solid-Phase Microextraction of Phenols. J. Sep. Sci. 2011, 34 (19), 2765-2772.

(58) Yeo, J. C. C.; Kai, D.; Teng, C. P.; Lin, E. M. J. R.; Tan, B. H.; Li, Z.; He, C. Highly Washable and Reusable Green Nanofibrous Sorbent with Superoleophilicity, Biodegradability, and Mechanical Robustness. ACS Appl. Polym. Mater. 2020. DOI: 10.1021/ acsapm.0c00786. 